\title{
Improvement Congestion Management in Deregulated Power System Considering Voltage Stability and Loss Minimization
}

\author{
Asmaa sobhy sabik, EL Saeed Osman, Mohamed Ebrahim El sayed
}

\begin{abstract}
First of the practical defiance's in unsystematized electrical networks is Congestion management. Two manners of percussions used in Congestion management are frill manners and cost free manners. In this paper work congestion is released by using cost free manners seeing (Flexible AC Transmission Systems) FACTS controller like SVC (Static Var compensator), STATCOM, TCSC (Thyristor controlled series Compensator), and SSSC (Static Synchronous Series Compensators) devices. Manifold-objective functions are presumed for congestion management. Small signal stability, voltage profile, and Real power loss reduction are considered objective functions in this paper. The optimal placement of FACTS controller are institute by using sensitivity founded Eigen value analysis and Continuation Power Flow (CPF). The suggested algorithm has used to define optimal placement of FACTS controller and deciphering optimal power flow (OPF) to advance voltage profile and minimize the real power losses within real and reactive power generation margin. The recital analysis has been implemented for IEEE 39 bus test system using MATLAB/PSAT (toolbox) software. Results display the suggested technique has a competency to advance the "Voltage profile, small signal stability, Loss minimization".
\end{abstract}

Keywords: Congestion management (CM), Optimal power flow (OPF), FACTS Devices, Continuation power flow (CPF).

\section{INTRODUCTION}

$\mathrm{W}_{\mathrm{i}}$ ith the significant increase in power demand in the few past decades, the size of the transmission network power have been improved in vertically integrated environment in addition to deregulated power sector. However, the CM and voltage instability problems are contestation concerns for the registered and consistent progression of power system. "The electrical power which pass on between two places in electrical grids is restricted by various safety norms for

Revised Manuscript Received on May 15, 2020.

* Correspondence Author

Eng A.S.S*, Teaching assistance in electrical power and machine department, AL- Azhar University. Email: Asmaasabik89@gmail.com

Prof. Dr. EL_ S. Osman, professor in electrical power and machine department, AL- Azhar University, Cairo, Egypt. Email: ghm_32@yahoo.com

Prof. Dr. M. E. El sayed, professor in electrical power and machine department, AL- Azhar University, Cairo, Egypt .Email: d_eng2009@yahoo.com”.

(C) The Authors. Published by Blue Eyes Intelligence Engineering and Sciences Publication (BEIESP). This is an open access article under the CC BY-NC-ND license (http://creativecommons.org/licenses/by-nc-nd/4.0/) instance voltage and stability margins. When electrical power unable pass on parts of network inasmuch the limits revealed, the system is alleged to be congested [1]". "Transmission congestion is a main challenge and can cause critical disturbances in the network. Solutions to alleviate congestion, generally denoted to as CM schemes, are of interest to both system recruiters and planners [2]". Thus, CM is about handling the electrical energy transmission and distribution among valuable consumers preference-wise. There are so many solvers available in the system for solving the problem of congestion associated with the (OPF) such as FACTS devices. OPF analysis is the baseline of power system study and plan. They are required for planning, implementation, profitable arrangement and argument of electrical energy between networks [3]. FACTS controller are implemented to upgrade the maximum load ability of the transmission network, excess the elasticity of electrical power network , makes it further manageable, and permits operation of prevailing grid closer to its thermal loading capacity without exposing the immovability. Voltage collapses stereotypically ensues on power systems that are profoundly loaded, faulted and/or have reactive power scarcity. The individual method to avoid the happening of voltage collapse is either to decrease the reactive power load or to deliver the system with further supply of reactive power before the system touches the point of voltage collapse [4]. FACTS techniques have the ability to enhancement the transferal receptivity in stability restricted systems by $20-30 \%$. As a result, further electrical energy can extent users with a smaller project operation time and a lesser investment cost [5]. Congestion in transmission refers to inability of transmission line (T.L) to deliver power to the desired customer due to simultaneous transactions or insufficient transmission capacity of T.L [6]. The literatures [7-8] have explained different methods and techniques of CM such as "Locational Marginal Price (LMP)" schemes. The simulation of the 39 bus system is implemented with and without using FACTS controller to overcome the congestion problems and the achieved consequences are compared thereafter.

\section{SYSTEM MODELING}

The IEEE 39-bus system is chosen to apply the idea of multi objectives of congestion management. The possibility of participating different loads on the management process will be investigated and the consequence of this process on the execution of the grid will be evaluated. The layout of IEEE 39-bus system is displayed in Figure (1). The description of this network is abridged in Table (I).

Published By:

Blue Eyes Intelligence Engineering \& Sciences Publication

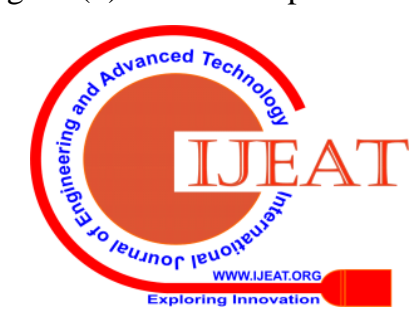




\section{Improvement Congestion Management in Deregulated Power System Considering Voltage Stability and Loss Minimization}

The studied system is IEEE 39-bus test system is consist of ten synchronous generators (SG). Real and reactive power are supplied by this SGs, it connected at Buses from 30 to 39, bus 31 is the slak bus. All generators have Automatic voltage regulators (AVR) and Turbine governor (TG) Type II. The model of the SG is VI order models. The system base load is 100 MVA. The base case of the model has dynamic order of 110.

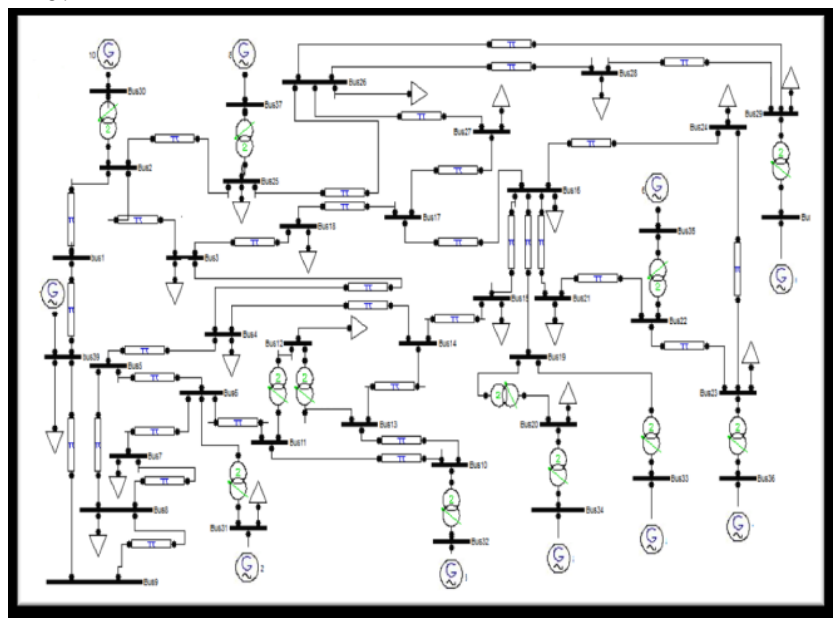

Fig.1. IEEE 39-bus test system

Table-I: System description

\begin{tabular}{|c|c|}
\hline Buses & 39 \\
\hline Generators & 10 \\
\hline Committed Gens & 10 \\
\hline Loads & 21 \\
\hline Branches & 46 \\
\hline Transformers & 12 \\
\hline
\end{tabular}

\section{OVER LOADING CONDITION FOR (CM) IN THE IMPLEMENTED GRID AND RESULTS ARGUMENTATION}

The grid gets congested when overloading condition but when the system under normal loading condition the grid is in stable condition. Here in the test system Overloaded condition is presumed. The Objective function of (OPF) can be done as a general constraints optimization problem as ensues decreasing of power losses and also enhance the voltage profile.

\section{A. Small Signal Stability of the Implemented Grid}

"Small signal stability is identified when small disturbances occurs in the system. The Implemented Grid is to conserve synchronism due to small disturbances. The equations (1) and (2) is a DAE (Differential Algebraic Equation) set that proposed for the small signal stability in PSAT":
$\mathrm{x}=\mathrm{f}(\mathrm{x}, \mathrm{y})$
$0=\mathrm{g}(\mathrm{x}, \mathrm{y})$

Here, $\mathrm{x}=$ vector of the state variable, $\mathrm{y}=$ vector of the algebraic.

B. comprehensible of Eigen Value in implemented Grid "System stability can be represented by the Eigen-values. The stability of the system is considered when Negative Eigen values are existed but when Positive Eigen value are presented the system enters to unstable mode.
Non-oscillatory mode and damping is represented by real Eigen values, but complex Eigen values are expressed to oscillatory mode and the frequency of the oscillation [9]".

C.Real Power Losses Minimization

This objective involves decreasing real power losses in implemented grid, it can be manifested as

$\mathrm{p}_{\text {loss }}=\min \left(\sum_{\mathrm{k}=1}^{\mathrm{NL}} \mathrm{g}_{\mathrm{k}}\left(\mathrm{V}_{\mathrm{i}}{ }^{2}+\mathrm{V}_{\mathrm{j}}{ }^{2}-2 \mathrm{~V}_{\mathrm{i}} \mathrm{V}_{\mathrm{j}} \cos \left(\delta_{\mathrm{i}}-\delta \mathrm{j}\right)\right)\right.$ where

$\mathrm{V}_{\mathrm{i}}, \mathrm{V}_{\mathrm{j}}$ is the voltage value at busi,j

$\mathrm{g}_{\mathrm{k}}$, is the conductance of line $\mathrm{i}, \mathrm{j}$

$\delta_{\mathrm{i}}, \delta \mathrm{j}$ is the voltage angle at bus $\mathrm{i}, \mathrm{j}$

$\mathrm{NL}$ is the whole number of transmission lines

\section{Voltage Profile enhancement}

Objective function for enhance the of load bus voltage (VP) can be cleared as:

$$
\mathrm{VP}=\sum_{\mathrm{k}=1}^{\text {Nbus }}\left|\mathrm{iV}_{\mathrm{k}}-\mathrm{V}_{\mathrm{k}}^{\text {ref }}\right|
$$

Where, $\mathrm{Vk}$ is the voltage value at bus $\mathrm{k}$.

"Equality constraints: The equality constraints of the OPF expressed active and reactive power between productions"

$$
\begin{aligned}
& \mathbf{P} \\
& { }_{\mathrm{Gi}}={ }_{\mathrm{Di}^{-}}+{ }_{\mathrm{L}}^{\mathbf{P}} \\
& \mathbf{Q}_{\mathrm{Gi}}=\mathbf{Q}_{\mathrm{Di}}+{ }_{\mathrm{L}}
\end{aligned}
$$

Inequality constraints: These are the sets of all operational power system elements (generator, transformer, and compensators from production source to load bus). Voltage limits:

$$
\mathrm{V}_{\mathrm{i}}^{\min } \leq \mathrm{V}_{\mathrm{i}} \leq \mathrm{V}_{\mathrm{i}}^{\max } ; \mathrm{i}=1,2 \ldots \mathrm{N} \text { no. of bus }
$$

Real power generation limits:

$$
\mathrm{P}_{\mathrm{gi}}{ }^{\min } \leq \mathrm{P}_{\mathrm{gi}} \leq \mathrm{P}_{\mathrm{gi}}{ }^{\max } ; \mathrm{i}=1,2 \ldots \mathrm{N} \text { no. of bus (8) }
$$

Reactive power generation limits:

$$
\mathrm{Q}_{\mathrm{gi}}{ }^{\mathrm{min}} \leq \mathrm{Q}_{\mathrm{gi}} \leq \mathrm{Q}_{\mathrm{gi}}{ }^{\max } ; \mathrm{i}=1,2 \ldots \mathrm{N} \text { no. of bus }
$$

\section{OPTIMAL ALOCATION OF FACTS CONTROLLER}

The (CPF) analysis is applied here in the figure below:

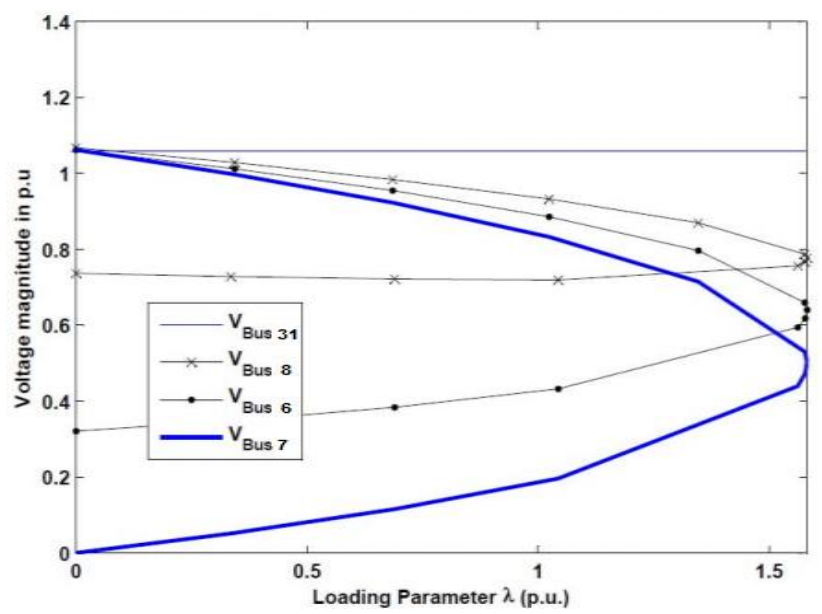

Fig. 2. PV curve of IEEE 39 bus system Without FACTS

Figure (2) observes that the voltage collapse happens at the maximum loading parameter of 1.5819 and voltage proportion of $0.473 \mathrm{p} . \mathrm{u}$ at bus no.7, So, the best location of SVC and STATCOM is bus no.7 and line 7-6 is gives best Line for shunt compensation.

\section{A. Location of Facts Devices Using PSAT CPF}

$\mathrm{CPF}$ technique is applied for carrying out voltage stability presentation analysis of the model under study.

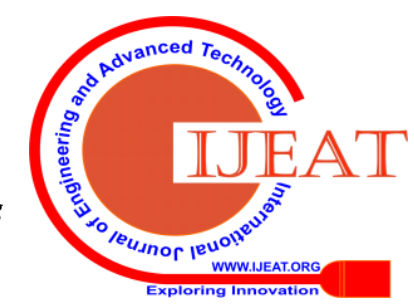



called loading margin. Loading margin is the maximum allowable load increase from the base load condition before the model enters voltage collapse. CPF also gives the wide-ranging PV curve of the grid buses. CPF is a precise approach for speculating the maximum loading limit and purposed the "weakest bus" When the voltage collapse happens. Simulation and it is done by using (PSAT). Several steps have been achieved the objectives, the step used to simulate the bus system.

a) Modeling the bus system by using PSAT

c) Execute the CPF and draw PV curve to find weak bus of the model

d) Observe the convenient placement of FACTS devices, so it gives best execution.

e) Obtained the voltage value at all buses and real power losses with and without using FACTS for OPF studies.

\section{V.V. CASES OF STUDY}

In this model IEEE 39 bus is get congested when connecting excess loads on the buses $7,16,3,12$. The weakest bus of the grid at over loading condition and has minimum voltage proportion has been identified bus 7 . So, this bus is the optimal place for FACTS devices. "So the small signal stability will be check by using Eigen values and tabulate the Eigen values with the positive or zero values with its dominant state".

\section{A. Small Signal Stability Analysis}

After the time domain simulation the Eigen values analyses are calculated for over loading condition. The results are shown in the table (II). This observes the system is in unstable condition due to overloading disturbance occur and no FACTS device connected because the positive Eigen values are exist. Connecting FACTS devices in the suitable place (bus 7 and line 7-6 best Line for shunt compensation) from the sensitivity based eigen value analysis a small signal stability is improved. The Results for applying FACTS device are tabulated, from the results the positive eigens are reduced from 1 to 0 and negative eigens are increased. So the network is maintained stable by using FACTS devices."

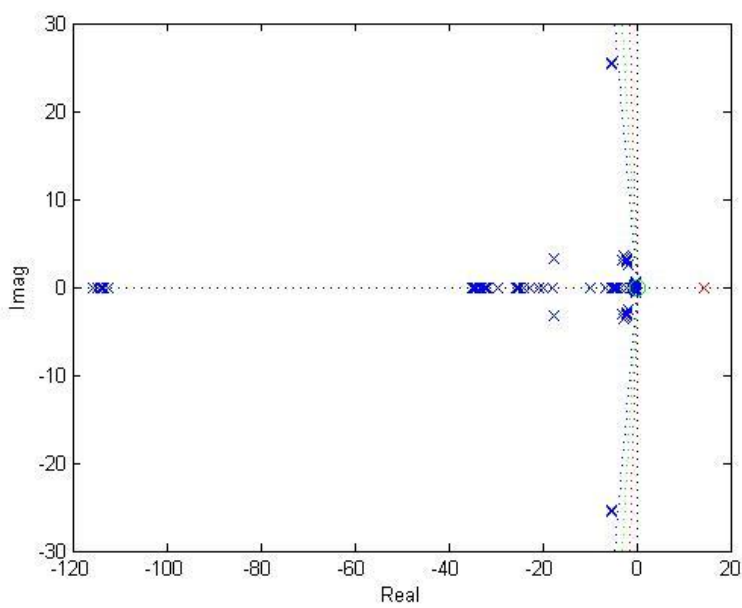

Fig. 3.Computed Eigen values of case for Overloaded condition without FACTS

As shown from figure (3) for IEEE 39 bus when over loaded condition without FACTS devices. The model has 110 Eigen numbers, all Eigen numbers are negative except the Eigen
This method gives voltage stability in provisos of a parameter

b) Implement the PF analysis (NR method).

number $(\lambda 21)$ is positive value and $\lambda 98$ is zero Eigen value in this case, so the model is unstable.

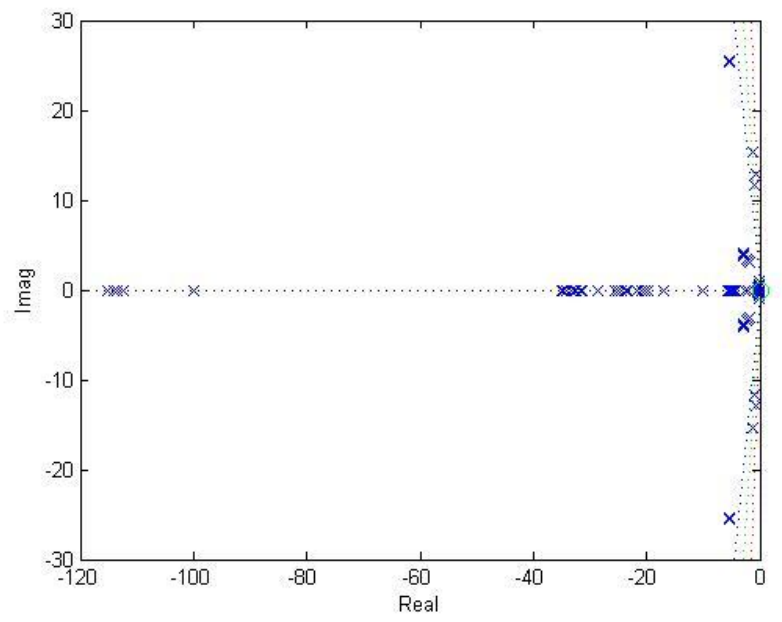

Fig. 4.Computed Eigen values of case for Overloaded condition and with SVC

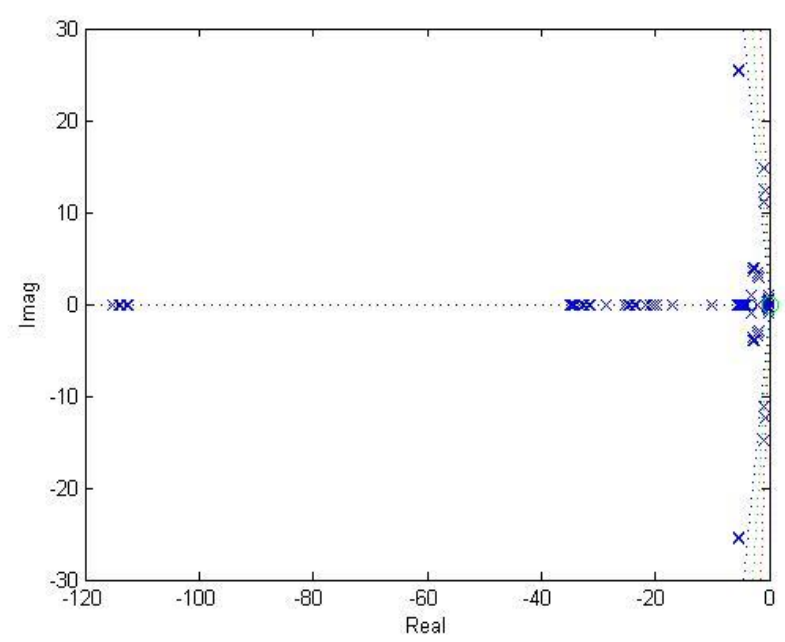

Fig. 5.Computed Eigen values of case for Overloaded condition and with STATCOM

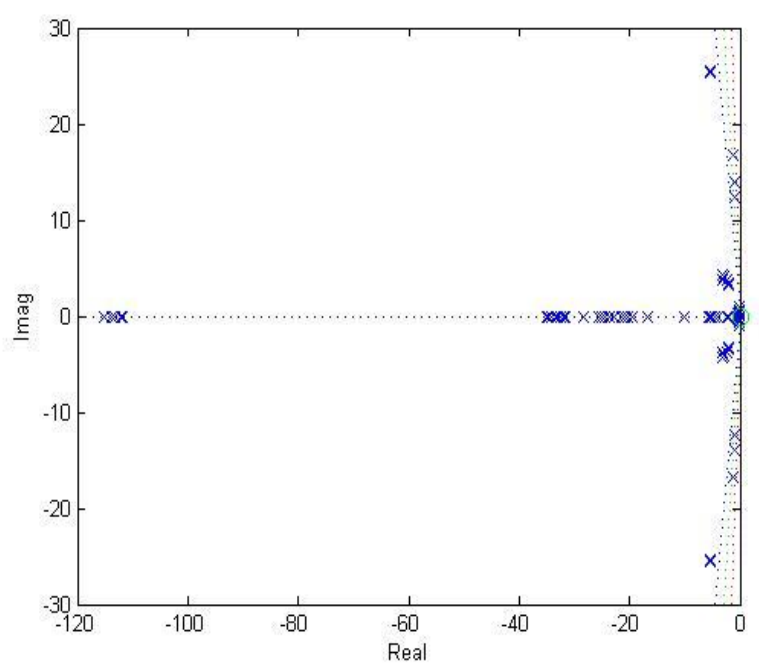

Fig. 6.Computed "Eigen values" of case for Overloaded condition and with SSSC

Published By:

Blue Eyes Intelligence Engineering

\& Sciences Publication

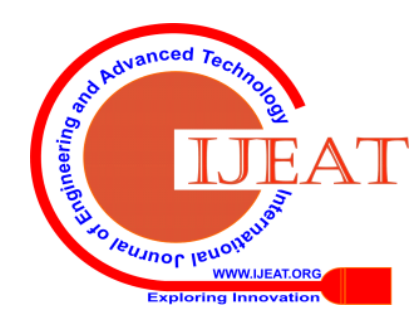




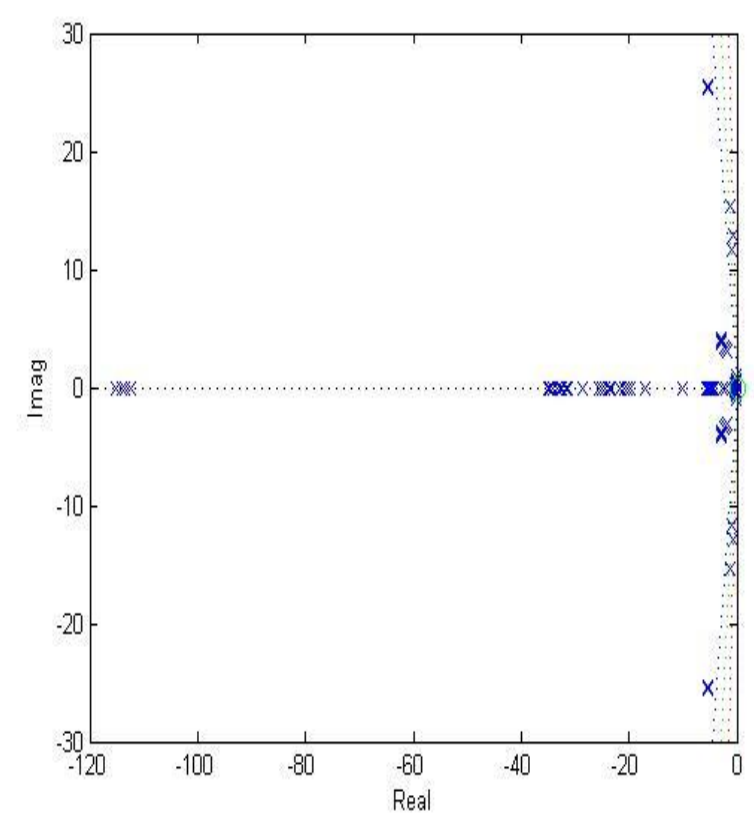

Fig. 7.Computed Eigen values of case for Overloaded condition and with TCSC

As shown from figures (4, 5, 6, and 7) for IEEE 39 bus system when over loaded condition without FACTS devices connected in the suitable place bus 7 for (SVC and STATCOM) and line 7-6 is gives best Line for (TCSC and SSSC). The results observed that the grid is maintained stable by using FACTS. Positive eigens are decreased from 1 to 0 and negative eigens are increased.

Table- II: Eigen Value Analysis of The grid over loading with and Without FACTS Devices

\begin{tabular}{|c|c|c|c|c|c|}
\hline & $\begin{array}{c}\text { Without } \\
\text { FACTS } \\
\text { Devices }\end{array}$ & $\begin{array}{c}\text { With } \\
\text { STATCO } \\
\mathbf{M}\end{array}$ & $\begin{array}{c}\text { WITH } \\
\text { TCSC }\end{array}$ & $\begin{array}{c}\text { With } \\
\text { SVC }\end{array}$ & $\begin{array}{c}\text { With } \\
\text { SSSC }\end{array}$ \\
\hline $\begin{array}{c}\text { Dynamic } \\
\text { order }\end{array}$ & 110 & 111 & 112 & 112 & 111 \\
\hline Buses & 39 & 39 & 39 & 39 & 39 \\
\hline $\begin{array}{c}\text { Posistive } \\
\text { eigs }\end{array}$ & 1 & 0 & 0 & 0 & 0 \\
\hline $\begin{array}{c}\text { Negative } \\
\text { eigs }\end{array}$ & 108 & 110 & 110 & 111 & 110 \\
\hline $\begin{array}{c}\text { Complex } \\
\text { pair }\end{array}$ & 26 & 30 & 29 & 29 & 29 \\
\hline $\begin{array}{c}\text { Zero } \\
\text { eigs }\end{array}$ & 1 & 1 & 2 & 1 & 1 \\
\hline
\end{tabular}

\section{B. Minimization of Power Losses}

The results are observed in table (III) the real power and reactive power losses are minimized by using FACTS. The summary report presents the total load and generation with losses. The results observes that the SSSC device is a good result comparable with other devices.
Table- III: Summary report over loading with and without FACTS

\begin{tabular}{|c|c|c|c|c|c|}
\hline $\begin{array}{c}\text { Total } \\
\text { power } \\
\text { generation }\end{array}$ & $\begin{array}{c}\text { Without } \\
\text { FACTS }\end{array}$ & SSSC & $\begin{array}{c}\text { STATCO } \\
\text { M }\end{array}$ & TCSC & SVC \\
\hline $\begin{array}{c}\text { Real } \\
\text { power } \\
\text { (pu) }\end{array}$ & 79.4458 & 79.2991 & 79.4351 & 79.3361 & 79.4351 \\
\hline $\begin{array}{c}\text { Reactive } \\
\text { power } \\
\text { (pu) }\end{array}$ & 70.9571 & 70.7342 & 70.8571 & 70.9437 & 70.8571 \\
\hline $\begin{array}{c}\text { Total } \\
\text { loads }\end{array}$ & Without & SSCTS & $\begin{array}{c}\text { STATCO } \\
\text { M }\end{array}$ & TCSC & SVC \\
\hline $\begin{array}{c}\text { Real } \\
\text { power } \\
\text { (pu) }\end{array}$ & 77.8097 & 77.8097 & 77.8097 & 77.8097 & 77.8097 \\
\hline $\begin{array}{c}\text { Reactive } \\
\text { power } \\
\text { (pu) }\end{array}$ & 16.3414 & 16.3414 & 16.3414 & 16.3414 & 16.3414 \\
\hline $\begin{array}{c}\text { Total } \\
\text { power } \\
\text { losses }\end{array}$ & FACTS & SSSC & $\begin{array}{c}\text { STATCO } \\
\text { M }\end{array}$ & TCSC & SVC \\
\hline $\begin{array}{c}\text { Real } \\
\text { power } \\
\text { (pu) }\end{array}$ & 1.6361 & $\mathbf{1 . 4 8 9 4}$ & 1.6254 & 1.5264 & $\mathbf{1 . 6 2 5 4}$ \\
\hline $\begin{array}{c}\text { Reactive } \\
\text { power } \\
\text { (pu) }\end{array}$ & 54.6157 & 54.1866 & 54.5157 & 54.6031 & 54.5157 \\
\hline
\end{tabular}

C. Voltage Stability Analysis

It is noticed from the Figure (8) the voltage proportion of the buses 5, 6, 7 and 8 are low comparable with other buses. The voltage profile at bus 7 with over loading condition without FACTS is reached $0.68048 \mathrm{pu}$ (the weakest bus) between the buses.

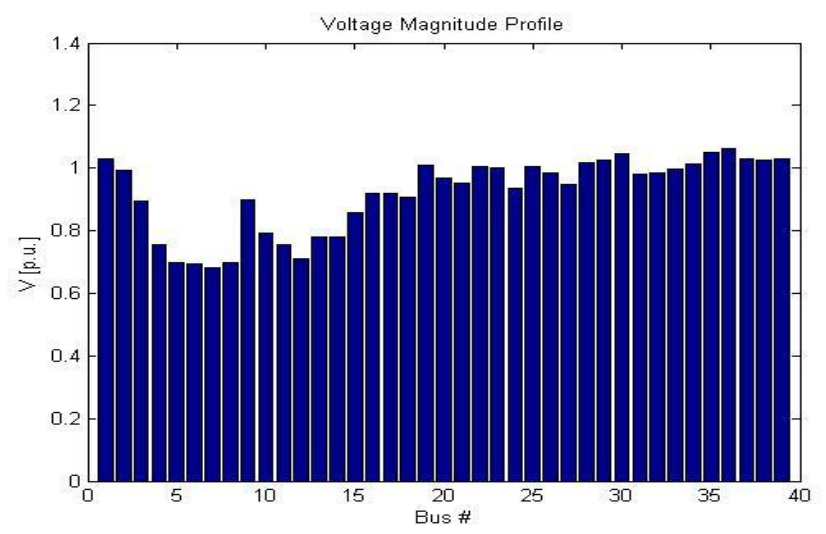

Fig. 8. Voltage Profile with over loading without FACTS

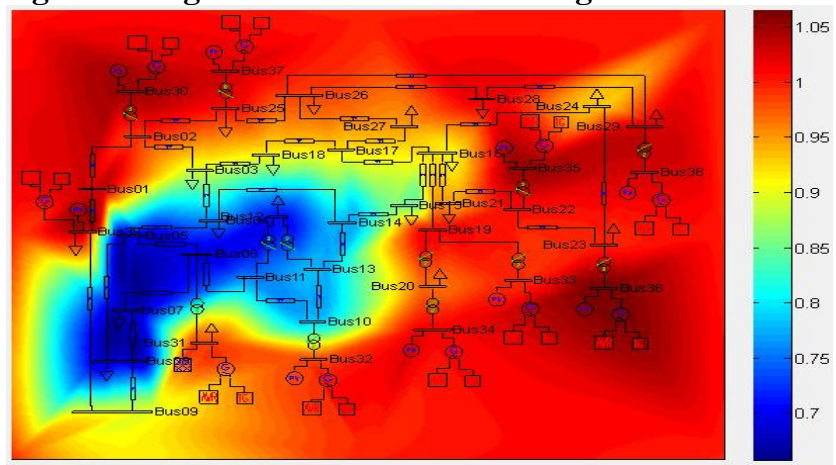

Fig 9. 2D View of Voltage magnitudes with over loading and without FACTS

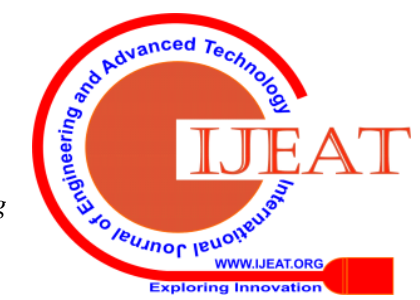


The bus 7 voltage has been identified that it has very low voltage magnitude and it became as the weakest bus of the implemented grid at over loading condition. So, this bus is the optimal allocation for applying STATCOM and SVC.

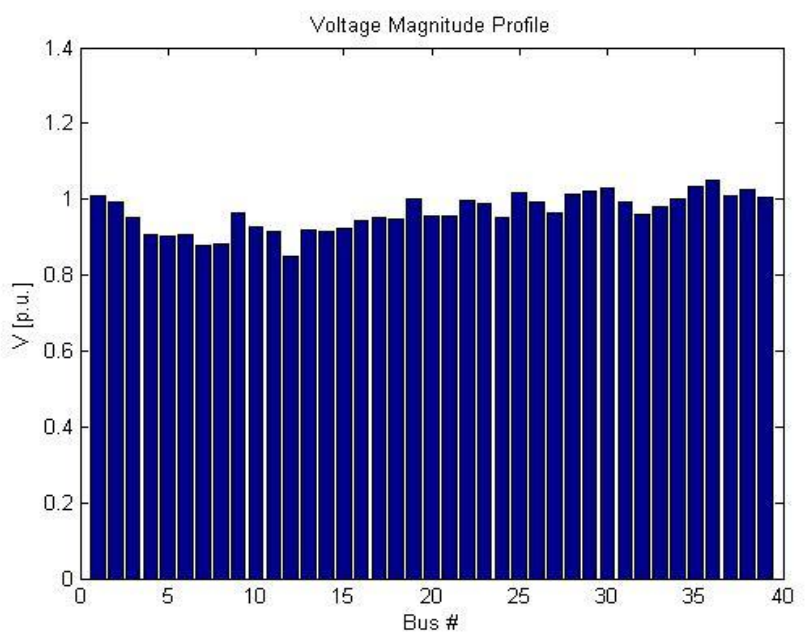

Fig. 10. Voltage magnitudes with over loading with STATCOM

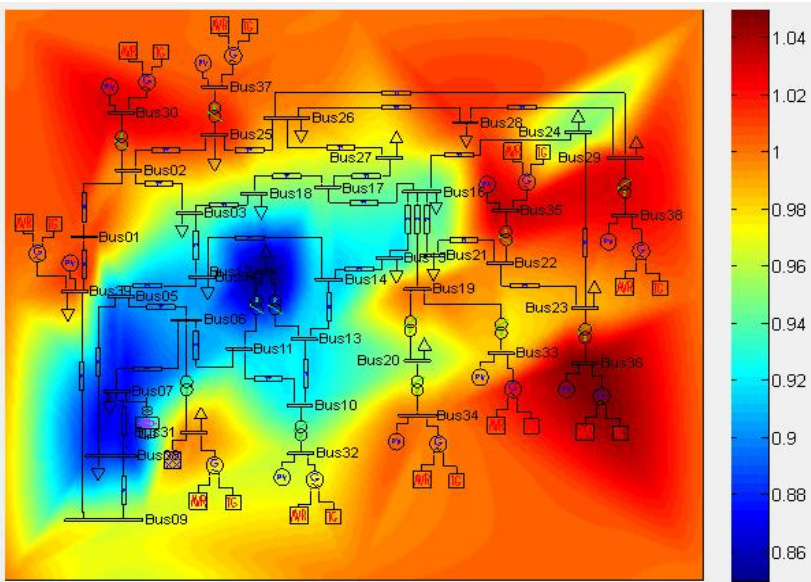

Fig. 11. 2D View of Voltage magnitudes with over loading and with STATCOM

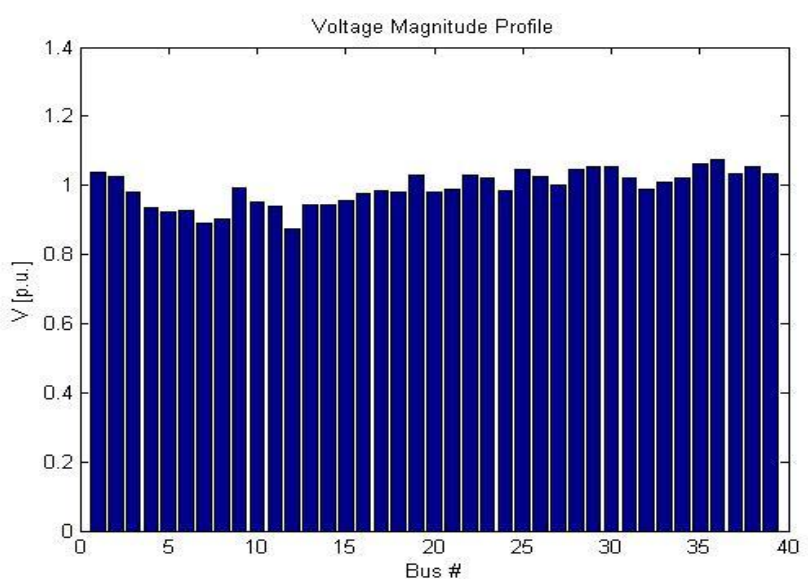

Fig. 12. Voltage magnitudes with over loading and with SVC

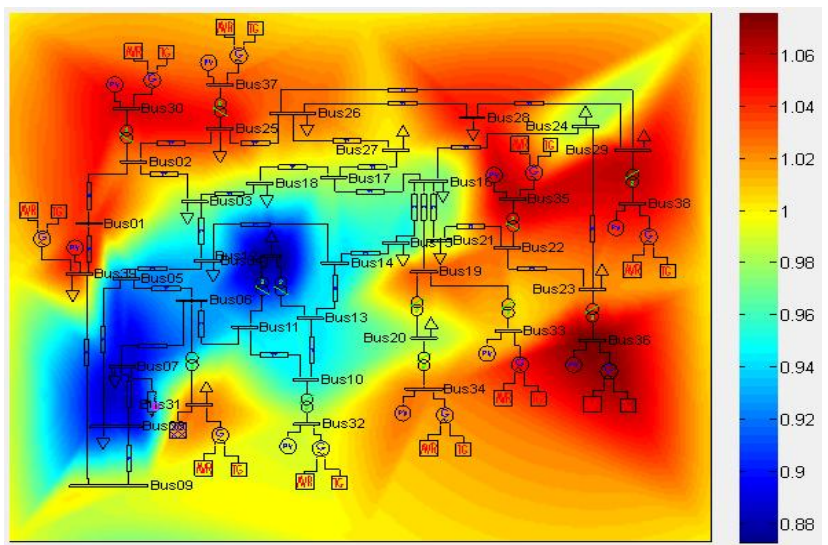

Fig. 13. 2D View of Voltage magnitudes with over loading and with SVC

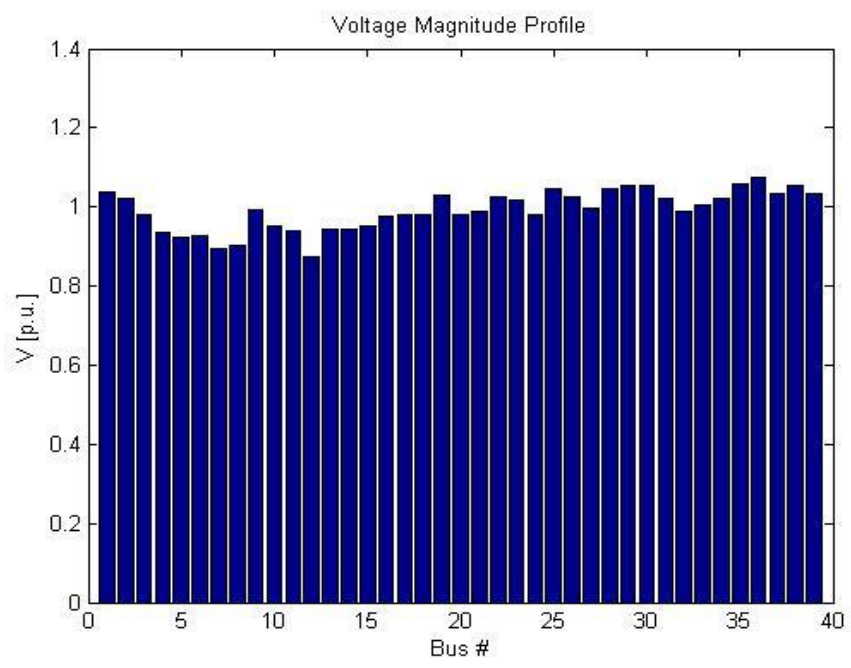

Fig. 14. Voltage magnitudes with over loading and with TCSC

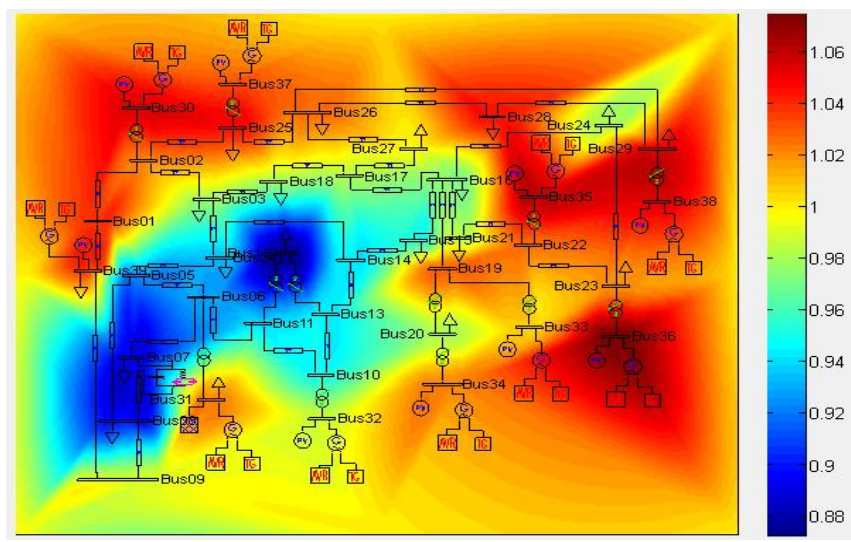

Fig. 15. 2D View of Voltage magnitudes with over loading and with TCSC

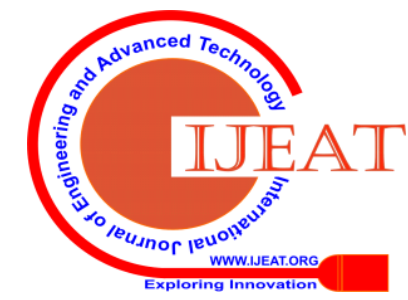




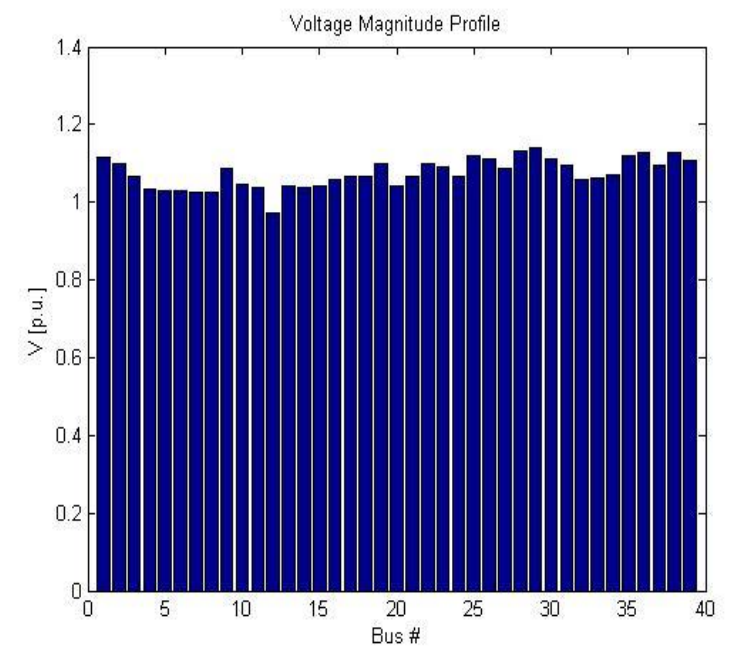

Fig. 16. Voltage magnitudes with over loading and with

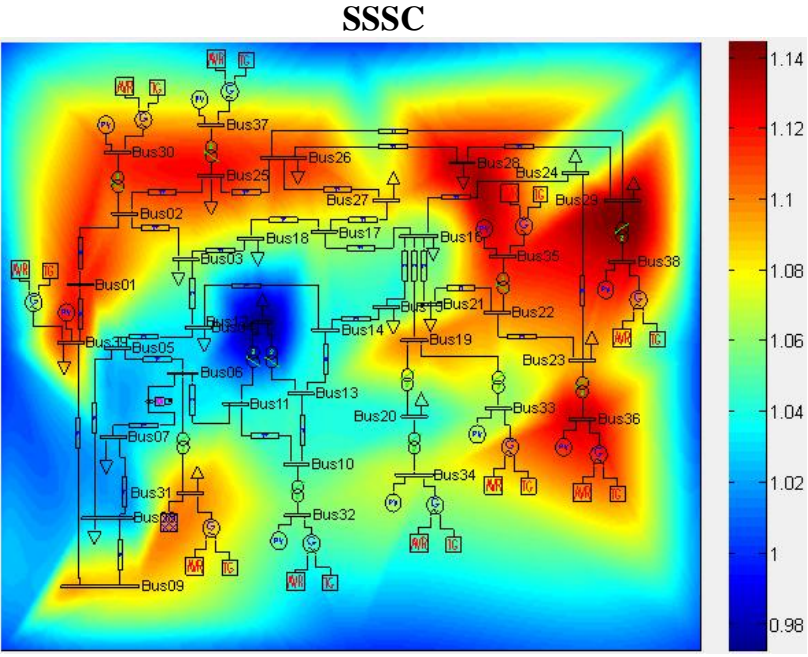

Fig. 17. 2D View of Voltage magnitudes with over loading and with SSSC

Figures (10, 12, 14, and 16) show the voltage proportion with FACTS devices. By locating STATCOM and SVC at bus 7, but (TCSC and SSSC) devices locating between bus7-8 and between bus (7-6) respectively. The voltage is sustained stable and which is in the allowable margin 0.9p.u to 1.1p.u.

Voltage profile magnitude

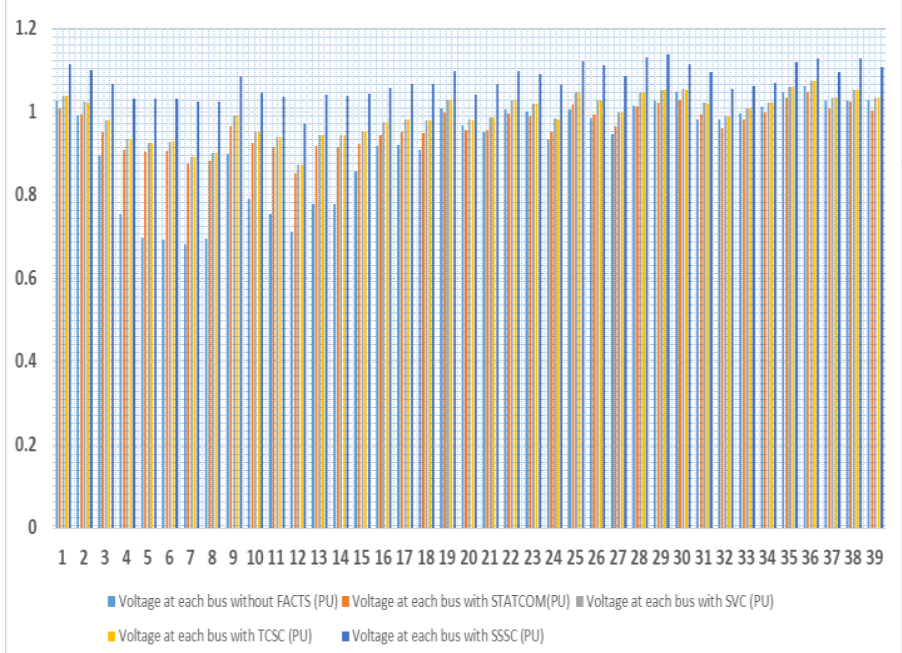

Fig. 18.Voltage profile magnitude comparison in 39 bus without and with FACTS for case (1)
Figure (18) shows the compared voltage level with and without FACTS controller. The voltage is sustained stable and the best result compared to other devices is SSSC controller.

\section{CONCLUSION AND FUTURE WORK}

In this work by using Matlab-PSAT toolbox multi-objective functions of CM solved by using FACTS controller like TCSC, STATCOM, SVC and SSSC devices. IEEE 39 bus model is taken here and tested it for overloading case, deregulated system is unstable and congested. FACTS devices are situated for the optimal location using CPF. The bus system voltage maintained stable, small signal stability improved and Power losses are reduced when using FACTS for CM. Comparing Overall performance SSSC give the best consequence compared with others. The future work can be implemented other multi objective functions for CM such as contingency analysis, locational marginal price and maximization social welfare using computational algorithms like Particle Swarm Optimization.

\section{ACKNOWLEDGMENT}

"A.S.S. Author likes to express her deep thanks and gratitude to Dr. EL Saeed Osman, Professor of Electrical Engineering, Faculty of Engineering, not only for suggesting the subject of this research work, but also for his close supervision, valuable guidance, help, encouragement, and kind criticism and also likes to express her deep thanks and gratitude to $\mathrm{Dr} /$ Mohamed Ebrahim El sayed, Professor of Electrical Engineering, for the supervision, continuous useful discussion, encouragement and motivation.

\section{REFERENCES}

1. H. Ahmadi, M. Khanabadi, and H. Ghasemi, "Transmission system reconfiguration for congestion management ensuring transient and voltage stability," 2013 13th Int. Conf. Environ. Electr. Eng. EEEIC 2013 - Conf. Proc., pp. 22-26, 2013.

2. Malado Diallo.1* , Livingstone Ngoo.2 , Michael Saulo. 3 , and Benaissa Bekkouche.4, “ Optimal Sizing of Grid-Tied Solar PV for Transmission Congestion Management in a Deregulated System using LMP Analysis," International Journal of Applied Engineering Research ISSN 0973-4562 Volume 14, Number 17 (2019) pp. 3598-3609.

3. M. Afkousi-Paqaleh · A. Abbaspour-Tehrani Fard · Masoud Rashidinejad, " Distributed generation placement for congestion management considering economic and financial issues,” Journal: 202 Article No.: 0175,2010.

4. K. Seetharamayya1 , M. Venkateswara Rao2 "Optimal Power Flow Studies Using FACTS Devices, ” 1 P.G Scholar, International Journal of Science and Research (IJSR), ISSN (Online): 2319-7064, Volume 4 Issue 9, September 2015.

5. A. Yuva Kishore1* and B. Guru Mohan3, "Enhancement of Voltage stability and Transmission Congestion management with UPFC," ISSN: 2005-4262 IJGDC, March 9, 2018.

6. P. L. L. Lai, "Power System Restructuring and Deregulation Trading, Performance and Information Technology", John Wiley \& Sons, Chichester, UK, (2001).

7. N. I. Yusof, A. A. M. Zin and A. B. Khairuddin, "Congestion Management in Power System: A Review", Proceedings of the 3rd International Conference on Power Generation Systems and Renewable Energy Technologies, (2017) April 4-6.

8. A. Pillay, S. Prabhakar Karthikeyan and D. P. Kothari, "Congestion management in power systems: a review", International Journal of Electrical Power and Energy Systems, vol.

9. Rahul Sagwala, Ashwani Kumarb *,"Congestion Management Solution for Hybrid System considering Voltage Stability

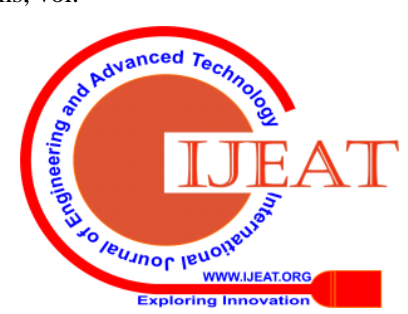


Margin", Recent Advancement and Effectual Researches in Engineering, Science and Technology (RAEREST), 25 ( 2016 ) 726 734.

\section{AUTHORS PROFILE}

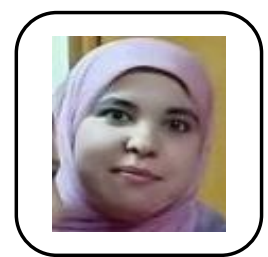

Eng. A.S.S received the Engineer degree in Electrical Engineering power and machine department from Al-Azhar University in 2012 and she received the Master's degree in renewable energy in 2017 from Al-Azhar University. She is currently doing as a teaching assistant in electrical engineering Dept. Her fields of interest include energy management, optimization, quality of power, and renewable energy.

Prof. Dr. EL_S. O, He is currently as Professor

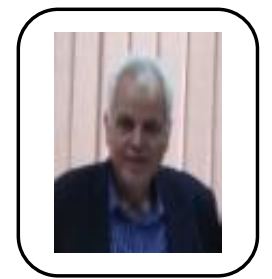

with the Department of Electrical Engineering AL_Azhar University, and He was the last Dean Faculty of engineering Al-Azhar University, Cairo, Egypt from 2007 to 2012. His current research interests include power system restructuring issues, ancillary service pricing, real and reactive power pricing, congestion management, and market clearing, including renewable energy sources, demand response, smart grid development with integration of wind and solar photovoltaic energy sources, artificial intelligence applications in power systems, and power system analysis and optimization.

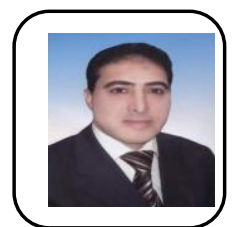

Prof. Dr. M. E. El_Sayed, received the Engineer and Magister degrees in Electrical engineering power and machine department from Al-Azhar University, in 1996 and 2002 respectively and the Ph.D. degree from Al-Azhar University, Egypt in 2006. Now he is working as professor in the department of Electrical Engineering and he is currently Manager of the Power Systems projects. His research interests include power electronics system modeling and control, power quality, and renewable energy integration research.

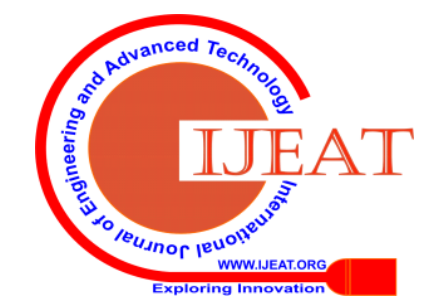

